\title{
Korrelationen zwischen Plasmareninaktivität und Blutdruck, Erythrocytenzahl, Hämoglobin, Hämatokrit sowie Natrium, Kalium, Harn- stoff und Kreatinin im Serum bei Hypertonikern ${ }^{1}$ )
}

\author{
Von C. Werning, W. Stiel, H. U. Schweikert, D. Stiel, W. Vetter und W. Siegenthaler \\ Aus der Medizinischen Universitäts-Poliklinik Bonn (Direktor: Prof. Dr. W. Siegentbaler)
}

(Eingegangen am 20. August 1970)

Bei 119 Patienten mit arterieller Hypertonie (66 Patienten mit essentieller Hypertonie, 31 mit renal-parenchymatöser Hypertonie, 16 mit renovaskulärer Hypertonie, 4 mit primärem Aldosteronismus, einer mit Aortenisthmusstenose und einer mit Polycythaemia vera) wurden die Korrelationen der Plasmareninaktivität zum systolischen und diastolischen Blutdruck, zum Natrium, Kalium, Harnstoff und Kreatinin im Serum sowie zur Erythrocytenzahl, Hämoglobin und Hämatokrit berechnet.

Im Gesamtkollektiv der Hypertoniker fand sich eine statistisch signifikante positive Korrelation der Plasmareninaktivität zum systolischen und diastolischen Blutdruck und zum Hämoglobin. Diese Bezichungen wurden auch bei den Patienten mit essentieller Hypertonie erhoben, bei denen zusätzlich eine signifikante positive Korrelation der Plasmareninaktivität zum Hämatokrit bestand. Bei den Patienten mit renovaskulärer Hypertonie war die Korrelation zwischen Plasmareninaktivität und Natrium im Serum signifikant.

Die übrigen Korrelationsberechnungen wiesen keine Signifikanz auf.

Die mögliche Bedeutung dieser Befunde wird diskutiert.

Correlations between plasma renin activity and blood pressure, red blood cells, bemoglobin, bematocrit, sodium, potassium, urea and creatinine in serum of bypertensive patients

In 119 patients with arterial hypertension ( 66 patients with essential hypertension, 31 with renal parenchymal diseases, 16 with renovascular hypertension, 4 with primary aldosteronism, one with coarctation of the aorta and one with polycythemia vera) correlations between plasma renin activity and systolic and diastolic blood pressure, sodium, potassium, urea and creatinine in serum and erythrocytes, hemoglobin and hematocrit were estimated.

In all patients a statistically significant positive correlation was found between plasma renin activity and systolic and diastolic blood pressure and also the hemoglobin. These correlations were also found in patients with essential hypertension, which further showed a significant positive correlation between plasma renin activity and hematocrit. In patients with renovascular hypertension the correlation between plasma renin activity and serum sodium was statistically significant.

The other estimations of correlations showed no statistical significance.

The possible importance of these results is discussed.

Die Plasmareninaktivität scheint in einer festen Beziehung zum arteriellen Blutdruck, zum Elektrolyt- und Wasserhaushalt oder zur Nierenfunktion zu stehen (1-5). So wurden zum Beispiel bei medikamentöser Blutdrucksenkung Exhöhungen der Plasmareninaktivität festgestellt (6), bei diuretika-induzierten Natrium-, Kalium- und Wasserverlusten traten deutliche Steigerungen der Plasmareninaktivität auf (7-9), und bei entzündlichen Schädigungen des Nierenparenchyms oder Niereninsuffizienz wurde eine vermehrte Reninsekretion nachgewiesen (10-13).

Weiterhin konnte beobachtet werden, daß zugleich mit dem Renin auch eine andere trenale humorale Substanz, das Erythropoetin, stimuliert werden kann (14-19), welche die Erythropoese und Hämoglobinsynthese fördert (20).

$\mathrm{Da}$ uns die Korrelationen der Plasmareninaktivität zu diesen verschiedenen Parametern interessierten, untersuchten wir bei Patienten mit arterieller Hypertonie die Beziehungen der Plasmareninaktivität zu Blutdruck,

1) Diese Arbeit wurde durch die Deutsche Forschungsgemeinschaft und das Landesamt für Forschung Nordrhein-Westfalen unterstützt.
Erythrocytenzahl, Hämoglobin und Hämatokrit sowie zum Natrium, Kalium, Harnstoff und Kreatinin im Serum.

\section{Patienten und Methodik}

Insgesamt wurden 119 Hypertoniker, und zwar 65 Männer und 54 Fraucn untersucht. Das Lebensalter schwankte zwischen 16 und 65 Jahren. Der Mittelwert betrug $45 \pm 11,5$ Jahre $(\bar{x} \pm s)$. 66 Patienten litten an einer essentiellen Hypertonie, die bei 14 Patienten als labile Hypertonie diagnostiziert wurde, während der Hochdruck bei 3 Patienten in die maligne Phase übergegangen war. Bei den übrigen Patienten konnte durch die entsprechenden Untersuchungen ein Grundleiden und somit eine sekundäre Hypertonie festgestellt werden.

So waren 16 Patienten an einer renovaskulären und 31 Patienten an einer tenal-parenchymatösen Hypertonie erkrankt. Von diesen 31 Patienten litten 15 an einer chronischen Pyeloncphritis, 8 an einer chronischen Glomerulonephritis, 4 an kongenitalen Nicrenmißbildungen wic Hypoplasien und Cysten, 3 an einem Hypernephrom und cin Patient an einem I upus erythematodes mit Nierenbeteiligung. Bei 4 Patienten wurde ein primärer Aldosteronismus nachgewiescn. Je ein Patient wies als Ursache der Hypertonic einc Aortenisthmusstenose bzw. einc Polycythaemia vera auf.

Eine manifeste Herzinsuffizienz oder pulmonale Erkrankungen lagen bei keinem det untersuchten Patienten vor. 
Die Plasmareninaktivität wurde nach der Methode von Boucher und Mitarbeitern (21) im peripheren venösen Blut bestimmt. Zur Korrelationsberechnung wurde lediglich der Basiswert nach mindestens vierstündiger Ruhelage des Patienten und bei normaler Kochsalzzufuhr verwandt (Normbereich: 0 bis $400 \mathrm{ng}$ Angiotensin II pro $100 \mathrm{ml}$ Plasma pro $3 \mathrm{Stdn}$. Inkubationsdauer).

Der Korrelationskoeffizient wurde nach der folgenden Gleichung berechnet:

$$
r=\frac{\sum x y-N \bar{x} \bar{y}}{\sqrt{\left(\sum \mathrm{x}^{2}-N \bar{x}^{2}\right)\left(\Sigma \bar{y}^{2}-N \bar{y}^{2}\right)}} .
$$

Die Prüfung auf Signifikanz des Korrelationskoeffizienten erfolgte anhand der $\mathrm{t}$-Verteilung mit $\mathrm{n}-2$ Freiheitsgraden:

$$
\hat{t}=\frac{r \sqrt{n-2}}{\sqrt{1-t^{2}}} .
$$

Die Regressionskoeffizienten ergaben sich aus den Gleichungen:

$$
A=\bar{y}-B \bar{x} \quad B=\frac{\sum x y-N \bar{x} \bar{y}}{\sum x^{2}-N \bar{x}^{2}} .
$$

Die Korrelationen wurden sowohl für das Gesamtkollektiv der Hypertoniker als auch für die Patientengruppen mit essentieller Hypertonie, renal-parenchymatöser und renovaskulärer Hypertonie aufgestelit. Die Ablehnung der Nullhypothese erfolgte bei einer Wahrscheinlichkeit von $\mathrm{p}<0,05$.

\section{Ergebnisse}

Die Plasmareninaktivität lag zwischen 35 und $980 \mathrm{ng} /$ $100 \mathrm{ml} \cdot 3 \mathrm{Stdn}$; im Mittel betrug sie $228 \pm 190 \mathrm{ng} /$ $100 \mathrm{ml} \cdot 3 \mathrm{Stdn}$. ( $\overline{\mathbf{x}} \pm \mathrm{s}$ ). Der Mittelwert der Patienten mit renovaskulärer Hypertonie bewegte sich mit $305 \pm 245 \mathrm{ng} / 100 \mathrm{ml} \cdot 3 \mathrm{Stdn}$. über denjenigen der $\mathrm{Pa}$ tienten mit renal-parenchymatöser Hypertonie (214 士 $142 \mathrm{ng} / 100 \mathrm{ml} \cdot 3 \mathrm{Stdn}$.) und mit essentieller Hypertonie $(236 \pm 219 \mathrm{ng} / 100 \mathrm{ml} \cdot 3 \mathrm{Stdn})$.

Der systolische Blutdruck schwankte zwischen 150 und $280 \mathrm{~mm} \mathrm{Hg}(192 \pm 29 \mathrm{~mm} \mathrm{Hg})$. Es bestand eine signifikante positive Korrelation zur Plasmareninaktivität $(\mathrm{r}=+0,263 ; 0,01>\mathrm{p}>0,001$ ) (siehe Abb. 1). Diese signifikante Korrelation fand sich in den einzelnen

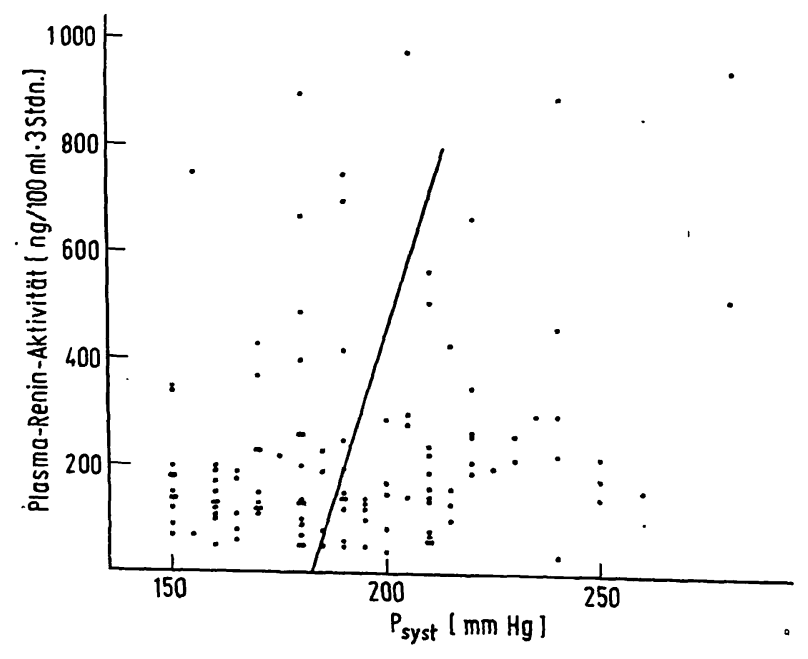

Abb. 1

Korrelation zwischen Plasmareninaktivität und systolischem Blutdruck bei Hypertonikern

$$
\begin{gathered}
y^{\prime}=182,71+0,04 x ; n=119, r=+0,263 \\
b>0,01 ! \\
p>0,001
\end{gathered}
$$

Gruppen lediglich bei den Patienten mit essentieller Hypertonie $(r=+0,256 ; 0,05>p>0,01)$. Der Korrelationskoeffizient betrug zwar bei den Patienten mit renovaskulärer Hypertonie + 0,388, war jedoch wegen der niedrigeren Patientenzahl statistisch nicht signifikant $(p>0,05)$.

Ähnlich verhielt sich der diastolische Blutdruck, der zwischen 90 und $190 \mathrm{~mm} \mathrm{Hg}$ schwankte (114 $\pm 17 \mathrm{~mm} \mathrm{Hg}$ ). Auch hier lag eine statistisch signifikante positive Korrelation zur Plasmareninaktivität vor $(r=+0,253$; $0,01>\mathrm{p}>0,001$ ) (siehe Abb. 2). Von den Patienten-

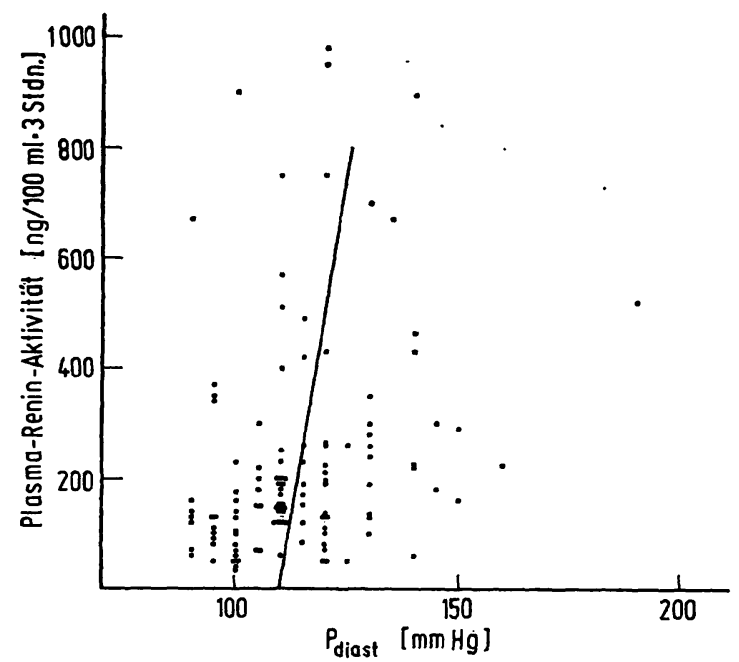

Abb. 2

Korrelation zwischen Plasmareninaktivität und diastolischem Blutdruck bei Hypertonikern

$$
\begin{aligned}
& y^{\prime}=109,02+0,02 x ; n=119, r=+0,253 \\
& . p>0,01 \\
&>0,001
\end{aligned}
$$

gruppen wiesen hier ebenfalls nur die essentiellen Hypertoniker eine signifikante positive Korrelation auf $(\mathrm{r}=+0,290 ; 0,05>\mathrm{p}>0,01)$

Der Korrelationskoeffizient von Plasmareninaktivität und Natrium im Serum, das sich zwischen 135 und $150 \mathrm{mVal} / \mathrm{l}$ bewegte (141 $\pm 3 \mathrm{mVal} / \mathrm{l})$, machte $+0,063$ aus und war statistisch nicht signifikant $(p>0,05)$. Allerdings konnte bei den Patienten mit renovaskulärer Hypertonie eine signifikante positive Korrelation nachgewiesen werden $(r=+0,509 ; 0,05$ $>\mathrm{p}>0,01$ ) (siehe Abb. 3), die bei den übrigen $z$ wei Patientengruppen nicht gefunden wurde.

Das Kalium im Serum betrug 2,5 bis $5,6 \mathrm{mVal} / l$. Der Mittelwert und die Standardabweichung lagen bei 4,2 $\pm 0,6 \mathrm{mVal} / \mathrm{l}$. Die Korrelation zur . Plasmareninaktivität war sowohl im Gesamtkollektiv ( $r=$ - 0,098; p > 0,05) (siehe Abb. 4) als auch bezüglich der 3 Gruppen der verschiedenen Hypertonieformen statistisch nicht signifikant.

Der Harnstoff im Serum, der Werte zwischen 18 und $265 \mathrm{mg} / 100 \mathrm{ml}$ zeigte, betrug im Mittel $44 \pm 29 \mathrm{mg} /$ $100 \mathrm{ml}$. Eine signifikante Korrelation zur Plasmareninaktivität bestand weder hinsichtlich des Gesamtkollektivss ( $r=-0,032 ; \mathrm{p}>0,05)$ (siehe Abb. 5) noch der einzelnen Patientengruppen.

Das Kreatinin im Serum bot ebenfalls zur Plasmareninaktivität keine statistisch signifikante Korrelation, 


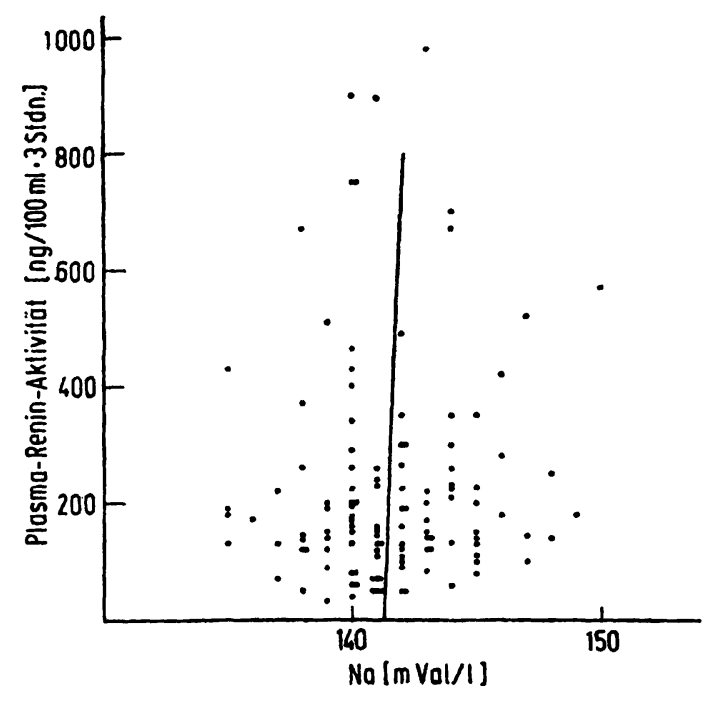

Abb. 3

Korrelation zwischen Plasmareninaktivităt und Serum-Natrium bei Hypertonikern $y^{\prime}=141,30+\underset{p}{0,001} x_{0,05}=119, r=+0,063$

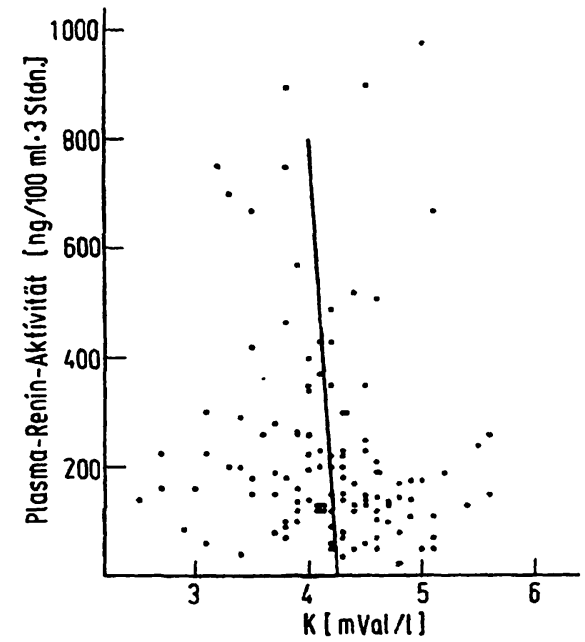

Abb. 4

Korrelation zwischen Plasmareninaktivität und Serum-Kalium be Hypertonikern $y^{\prime}=4,248-0,0003 x ; n=119, r=-0,098$



Abb. 5

Korrelation zwischen Plasmareninaktivität und Serum-Harnstoff bei Hypertonikern

$$
y^{\prime}=45,00-0,005 x ; n=119, r=-0,032
$$

dic für die Hypertoniker insgesamt mit dem Koeffizienten $r=+0,015(p>0,05)$ berechnet wurde (siehe Abb. 6). Die Einzelwerte schwankten zwischen 0,7 und $12,7 \mathrm{mg} / 100 \mathrm{~m} /$; im Mittel lagen sie bei 1,55 $\pm 1,47 \mathrm{mg} / 100 \mathrm{~m} /$.

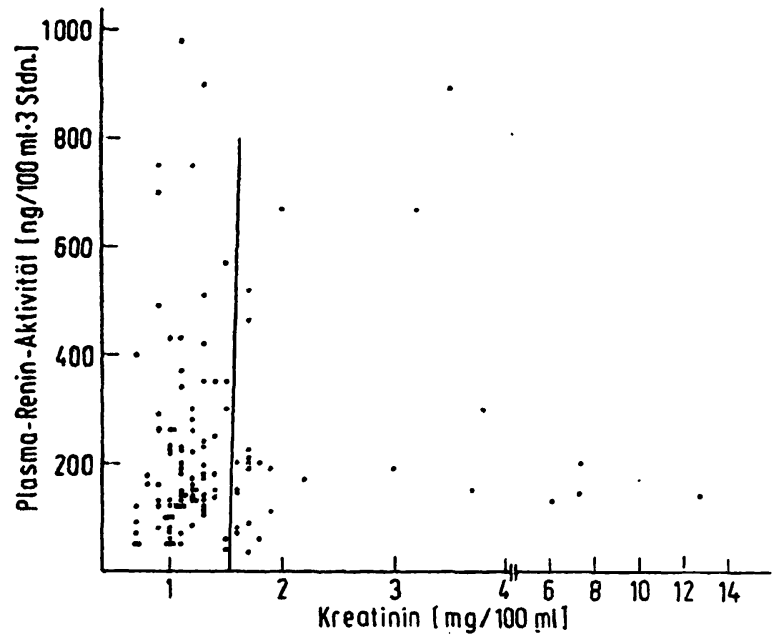

Abb. 6

Korrelation zwischen Plasmareninaktivität und Serum-Kreatinin bei Hypertonikern

$$
y^{\prime}=1,526+\underset{p}{0,0001} x_{j} n=119, r=+0,015
$$

Die Erythrocytenzablen betrugen 2,9 bis $7,1 \cdot 10^{6} \mathrm{~mm}^{3}$ $\left(4,7 \pm 0,6 \cdot 10^{6} \mathrm{~mm}^{3}\right)$. Der Korrelationskoeffizient von Erythrocyten und Plasmareninaktivität war mit $+0,107$ statistisch nicht signifikant $(p>0,05)$ (siehe Abb. 7). Diese Berechnung der Signifikanz galt für alle drei untersuchten Hypertoniearten.

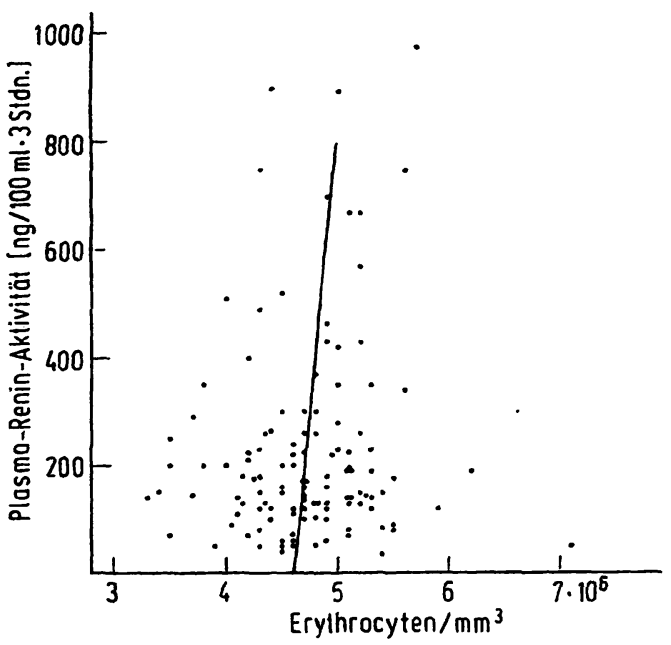

Abb. 7

Korrelation zwischen Plasmareninaktivität und Erythrocytenzahl bei Hypertonikern

$$
y^{\prime}=4,624+\underset{p}{0,0003} x_{j} n=119, r=+0,107
$$

Das Hämoglobin schwankte zwischen 9,3 und $23,2 \mathrm{~g} /$ $100 \mathrm{ml}(14,8 \pm 2,1 \mathrm{~g} / 100 \mathrm{~m} /)$. Hier konnte eine statistisch signifikante positive Korrelation zur Plasmareninaktivität gefunden werden $(r=+0,199 ; 0,05>$ $\mathrm{p}>0,01$ ) (siehe Abb. 8). Diese kam deutlicher bei den Patienten mit essentieller Hypertonie zum Ausdruck $(r=+0,335 ; 0,01>p>0,001)$, während die beiden 


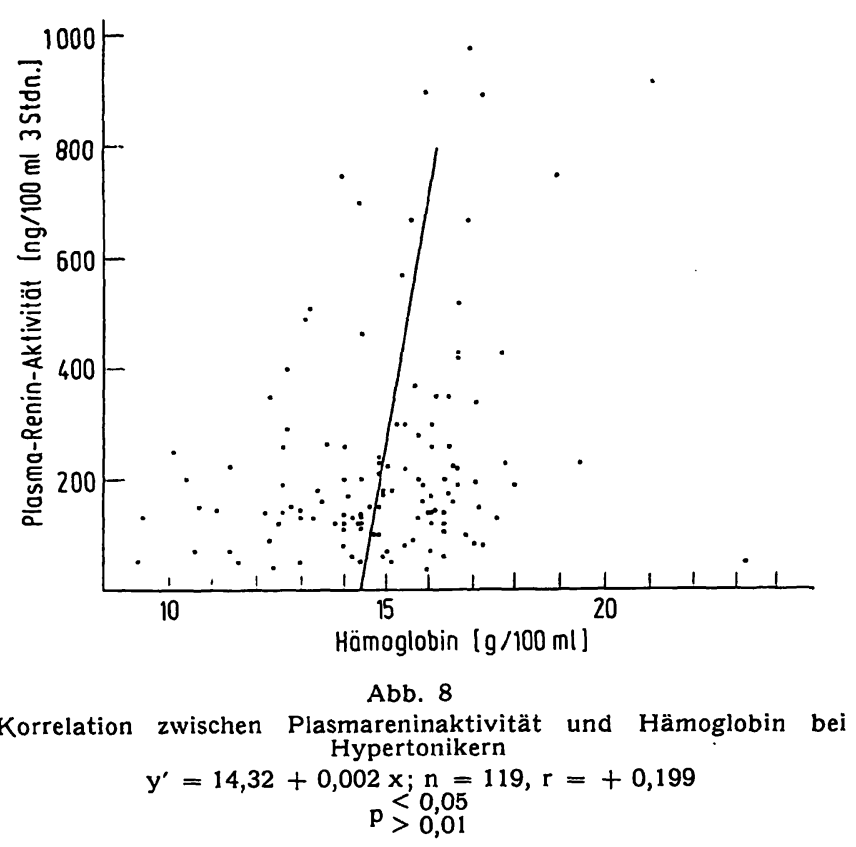

übrigen Patientengruppen keine statistisch signifikanten Korrelationèn zeigten.

Schließlich wurde die Korrelation der Plasmareninaktivität zum Hämatokrit berechnet. Es konnte bei den Patienten mit essentieller Hypertonie eine statistisch signifikante positive Korrelation gefunden werden $(r=$ $+0,299 ; 0,05>p>0,01)$. Bei den Patienten mit renal-parenchymatöser Hypertonie und renovaskulärer Hypertonie war ebenso wie bei dem Gesamtkollektiv der Hypertoniker ( $r=+0,141 ; \mathrm{p}>0,05)$ (siehe Abb. 9) eine Signifikanz der Korrelation nicht nachweisbar. Die Einzel-Hämatokritwerte schwankten zwischen 28 und $71 \mathrm{Vol} \%$. Der Mittelwert betrug 44,6 $\pm 5,7 \mathrm{Vol} \%$.

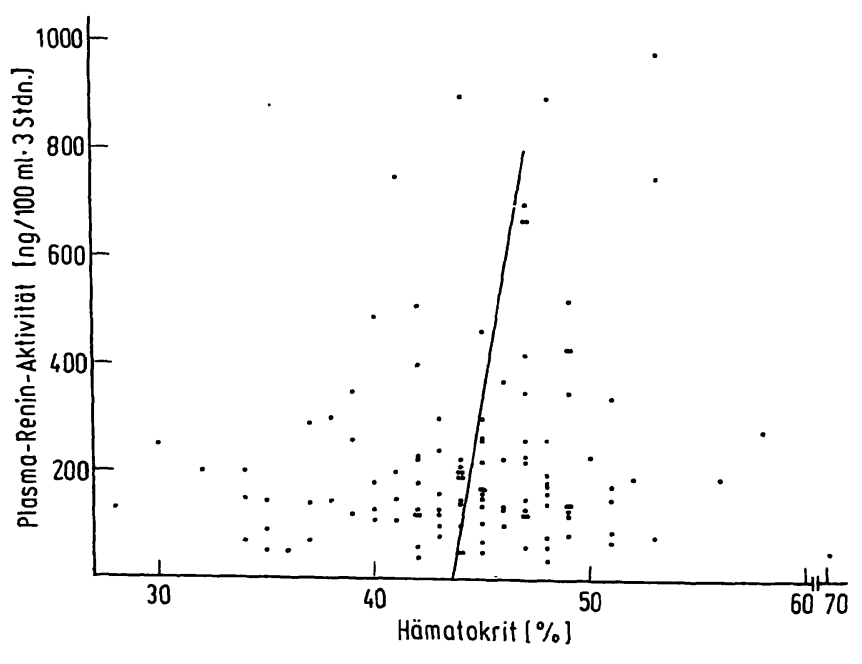

Korrelation zwischen Plașmareninaktivität und Hämatokrit bei $\mathrm{y}^{\prime}=43,61+0,004 \mathrm{x} ; \mathrm{n}=119, \mathrm{r}=+0,141$

\section{Diskussion}

Bei unseren statistischen Berechnungen der Korrelationen zwischen der Plasmareninaktivität und verschiedenen Parametern fiel zunächst auf, daß bei dem Gesamtkollektiv der Hypertoniker eine signifikante posi- tive Korrelation der Plasmareninaktivität zum systolischen und diastolischen Blutdruck bestand. Diese Korrelation bedeutet selbstverständlich nicht ohne weiteres eine pathophysiologische oder pathogenetische Beziehung zwischen den beiden Größen. Es ist allerdings bemerkenswert, da $\beta$ die Korrelation vor allem bei den Patienten mit essentieller Hypertonie signifikant war. Man hätte eher bei den Patienten mit renovaskulärer Hypertonie diese positive Beziehung erwarten dürfen, da bei dieser Hypertonieform das Renin höchstwahrscheinlich eine wesentliche pathogenetische Bedeutung besitzt $(5,22)$. Bei der renovaskulären Hypertonie braucht jedoch der Basiswert der Plasmareninaktivität im Gegensatz zu den Stimulationswerten nach Gabe von Saluretika oder aktiver Orthostase nicht regelmäßig erhöht gefunden $z u$ werden $(5,22)$. Bei Patienten mit essentieller Hypertonie ist die Plasmareninaktivität meistens normal oder sogar erniedrigı (5). Möglicherweise ist die Tatsache, daß sich in dieser Gruppe die Patienten mit maligner Hypertonie befanden, für die berechnete Signifikanz verantwortlich. Diese Patienten wiesen sehr hohe Reninwerte auf, wie man es bei der Akzeleration einer arteriellen Hypertonie findet $(4,5)$.

Es ist eher unwahrscheinlich, daß die gefundene Korrelation in dem Sinne zu deuten ist, daß bei unseren $\mathrm{Pa}-$ tienten mit essentieller Hypertonie dem Renin bzw. Angiotensin eine pathogenetische Bedeutung zukommt, zumal auch die Beziehungen zwischen Renin und Blutdruck völlig unterschiedlich sein können $(4,9)$. Es ist allerdings von Interesse, da $\beta$ auf Grund von Tierexperimenten das Angiotensin auch schon bei normalem Blutdruck eine wichtige pressoregulatorische Funktion $\mathrm{zu}$ besitzen scheint (23).

Die Beziehungen zwischen der Plasmareninaktivität und den Elektrolyten Natrium und Kalium im Serum zeigten keine Signifikanz, abgesehen von der statistisch signifikanten positiven Korrelation zwischen der Plasmareninaktivität und dem Serum-Natrium bei den Patienten mit renovaskulärer Hypertonie. Eventuell sind ein sekundärer Hyperaldosteronismus, den man bei renovaskulärer Hypertonie antreffen kann $(24,25)$, oder auch eine direkte natriumretinierende Angiotensin-Wirkung (26) als ưrsạchlich für dieses Phänomen anzusehen. Hier muß man jedoch ebenfalls feststellen, daß die Beziehungen zwischen der Plasmareninaktivität und den Elektrolyten völlig divergent sein können. So stimulieren zum Beispiel einerseits Natrium- und Kaliumverluste die Plasmareninaktivität (7-9), während man andererseits bei einer Hypernatriämie im Rahmen eines Diabetes insipidus (27) oder bei einer Hyperkaliämie im Verlauf eines Morbus Addison (7) eine Hyperreninämie antreffen kann.

Harnstoff und Kreatinin im Serum wurden zur Plasmareninaktivität korreliert, um eventuell festzustellen, ob der Grad einer Niereninsuffizienz zur Höhe der Plasmareninaktivität in einer bestimmten Beziehung steht. Dabei wurde weder im Gesamtkollektiv der Hypertoniker noch in den Einzelgruppen eine Signi- 
fikanz nachgewiesen. Diese Befunde stehen in Einklang mit den Ergebnissen verschiedener Autoren, die bei chronischer Niereninsuffizienz sowohl hohe wie auch normale oder niedrige Plasmareninaktivitäten fanden (11, 13, 28). In Einzelfällen darf man allerdings annehmen, $\mathrm{da} B$ das Renin stimuliert wird, wenn durch Nierenparenchymveränderungen die renale Hämodynamik gestört wird (2), und daß die Hypertonie bei chronischer Niereninsuffizienz durch das Renin-Angiotensin-System hervorgerufen werden kann $(11,13,28)$. Dafür spricht insbesondere die Beobachtung, da $\beta$ bei den Patienten mit chronischem Nierenleiden, die hohe Reninwerte aufweisen, nur eine bilaterale Nephrektomie zur effektiven Blutdrucksenkung führt $(11,13,28)$.

Renin und Erythropoetin bzw. der renale erythropoetische Faktor werden höchstwahrscheinlich in denselben Zellen, und zwar in den granulierten Zellen des juxtaglomerulären Apparates der Niere gebildet. Mehrere Untersuchungsergebnisse deuten darauf hin, da $\beta$ beide humorale Substanzen gleichzeitig stimuliert werden können, obwohl sie unterschiedlichen Regulationsmechanismen unterliegen $(18,19)$. Zum Beispiel wurden beim experimentellen Niereninfarkt (14), bei der Abstoßungskrise von Nierentransplantaten im Kaninchenexperiment (15) sowie bei Patienten mit renovaskulärer Hypertonie (16) oder mit BARTter-Syndrom (17) hohe Werte beider Hormone gefunden. Uns interessierte die Frage, ob bei den Hypertonikern eine signifikante Korrelation zwischen Renin und Erythropoetin besteht. $\mathrm{Da}$ wir das Erythropoetin nicht direkt bestimmen konnten, untersuchten wir indirekte Parameter wie die
Erythrocytenzahl, das Hämoglobin und den Hämatokrit. Bekanntlich fördert Erythropoetin die Bildung von Erythrocyten und die Synthese von Hämoglobin (20).

Tatsächlich bestand im Gesamtkollektiv der Hypertoniker eine statistisch signifikante positive Korrelation der Plasmareninaktivität zum Hämoglobin. Von den 3 Gruppen wiesen nur die Patienten mit essentieller Hypertonie diese signifikante Beziehung auf, wobei hier zusätzlich noch eine signifikante positive Korrelation zum Hämatokrit vorlag. Es muß offenbleiben, wie diese Befunde $z u$ interpretieren sind, bzw. ob bei Patienten mit essentieller Hypertonie Renin- und Erythropoetinspiegel in einer festen Beziehung zueinander stehen. Bisher ist im Gegensatz zum Renin nicht bekannt, wie sich das Erythropoetin bei der essentiellen Hypertonie verhält.

Der Hämatokrit dürfte sicher noch durch andere Faktoren als das Erythropoetin beeinflußt worden sein, zum Beispiel durch das Plasmavolumen, das bei fortschreitender Schwere einer arteriellen Hypertonie und Erhöhung des peripheren Gefäßwiderstandes eine zunchmende Reduktion erkennen läßt (29). Falls der bei unseren Hypertonikern gemessene Hämatokrit Rückschlüsse auf das Plasmavolumen zuläßt, unterstützt die beobachtete positive Beziehung zwischen der Plasmareninaktivität und dem Hämatokrit die These, $\mathrm{da} B$ dem Volumen bei der Regulation der Reninsekretion eine wesentliche Bedeutung zukommt $(9,18,27)$.

Wir danken unseren technischen Assistentinnen Frl. M. AppeNhermer, Frl. B. Haupt, Frau R. Kowalski, Frl. E. Leuschner, Frl. I. Richters und Ftl. H. WeinNd für ihre wertvolle Hilfe.

\section{Literatur}

1. Brown, J. J., D. L. Davies, A. F. Lever und J. I. S. RobertSON, Brit. med. J. 1965, 144. - 2. HollendBERG, N. K., M. EPSTEIN, R. I. Basch, J. P. Merrill und R. B. Hickler, Circulat. Res. Suppl. 24 und 25, 1-113 (1969). - 3. NewSOME, H. H. und F. C. BARTter, J. clin. Endocr., Springfield 28, 1704 (1968). 4. Siegenthaler, W. und C. Werning, Dtsch. med. Wschr. 95, 411 (1970). - 5. Werning, C., P. WeidmanN, W. Vetter, D. Stiel, H. U. Schweikert und W. Stegenthaler, Schweiz. Rundsch. Med. 59,730 (1970). - 6. KANEKo, Y., T. IKEDA, T. TAKEDA, G. InOUe, H. TAgawa und H. Ueda, Circulation 38, 353 (1968). 7. Werning, C., K. Baumand, E. Gysling, M. Schönbeck, P. Weidmann und W. Sxegenthaler, Arzneimittel-Forsch., Aulendorf 20, 1935 (1970). - 8. Werning, C., K. BaumanN, M. SchönBeck, E. Gysing, P. WeidmanN und W. Stegenthaler, Klin. Wschr. 47, 318 (1969). - 9. Werning, C., W. Vetrter, H. U. Schweikert, P. WeidmanN, D. Stiel und W. Siegenthaler, Klin. Wschr. 48, 1047 (1970). - 10. BiR KENHÄgER, W. H., M. A. D. H. Schalekamp, M. P. A. SchaleKamp-Kuyken, G. Kolsters und X. H. Krauss, Lancet, London 1970/I, 1086. - 11. Brown, J. J., J. R. Curtis, A. F. Lever, J. I. S. Robertson, H. E. de WARDENER und A. J. Wing, Nephton 6, 329 (1969). - 12. Tu, W. H., Circulation 31, 686 (1965). - 13. Vertes, V., J. L. CaNglano, L. B. Berman und A. Gould, New Engl. J. Med. 280, 978 (1969). - 14. Abbrecht, P. H., R. L. Malvin und A. J. VANDER, Nature (London) 211, 1318 (1966). - 15. ABbrecht,
P. H., J. G. Turcotte und A. J. VANDER, J. Laborat. clin. Med. S. Louis 71, 766 (1968). - 16. Bourgoignie, J. J., N. I. Gallagher, H. M. Perry jr., L. Kurz, M. A. Warnecke und R. M. Donati, J. Jaborat. clin. Med., S. Louis 71, 523 (1968). - 17. Jepson, J. und E. E. McGarry, Blood 32, 370 (1968). - 18. Werning, C., U. Essers, P. Schulte, H. U. Schweikert, D. Stiel, W. Vetter, P. WeidmanN und W. Siegenthaler, Klin. Wschr. (im Druck). - 19. Werning, C. und W. Siegenthaler, Schweiz. med. Wschr. 100, 1897 (1970). - 20. Krantz, S. B., Med. Clin. North Amer. 54, 173 (1970). - 21. Boucher, R., R. Veyrat, J. De Champlain und J. Genest, Canad. med. Ass. J. 90, 194 (1964). - 22. Werning, C., H. U. Schweikert, D. Stiel, W. Vetter, P. WeidmanN und W. Siegentialler, Med. Welt 21, (im Druck) (1970). - 23. WorCed, M., P. Meyer, G. A. D'Auriac und P. Mruliez, Pflügers Arch. ges. Physiol. 310, 251 (1969). - 24. Siegenthaler, W., C. Werning, P. Weidmann, D. Stiel und W. Vetrer, Med. Klin. 65, 1149 (1970). - 25. Werning, C. und W. Siegenthaler, Dtsch. med. Wschr. 94, 2049 (1969). - 26. Werning, C. und W. Siegenthaler, Klin. Wschr. 47, 1247 (1969). - 27. Werning, C., K. BaumanN, P. Weidmand, E. Gysling und W. Siegentrialer, Schweiz. med. Wschr. 99, 661 (1969). - 28. Stokes, G. S., M. K. Mani und J. H. Steivart, Brit. med. J. 1970/III, 126. - 29. T'Arazr, R. C., E. D. Frohlich und H. P. Dus'ran, New Engl. J. Med. 278, 762 (1968).

Priv.-Doz.Dr. med.C. Werning cand. med. W. Stiel Dr. med. H. U. Schweikert

Dr. med. D. Stiel Dr. med. W. Vetter Prof. Dr. med. W. Siegenthaler Medizinische Universitäts-Poliklinik 53 Bonn, Wilhelmstraße 35-37 